\title{
Development of Fetal Heart Rate Control in Diabetic Pregnancies Determined by Nonstress Test
}

\author{
TEIJI HAMADA, TAKAMOTO MATSUNAGA, JUNJI ISHIMATSU, \\ TAKATSUGU MATSUNAGA, NORIO KUBO AND TOSHI KATO \\ Department of Obstetrics and Gynecology, Kurume University School of Medicine, \\ Kurume, 830 Japan
}

Received for publication July 10, 1985

\begin{abstract}
Summary: It has been considered that the control mechanism of FHR is regarded by its central nervous system (CNS). Our attempt were focused on the differences of FHR changes between normal fetuses and fetuses of diabetic mothers. A hundred and fifteen normal fetuses (24 to 36 gestational weeks) and 16 diabetic mothers (28 to 36 gestational weeks) were investigated by means of NST. Since acceleration associated fetal movement increased significantly from 28 to 36 gestational weeks in normal fetuses, control mechanism of FHR regulated by CNS was regarded to be established in this period. Increasement of the acceleration was also observed after 28 gestational weeks in fetuses of diabetic mothers. The acceleration of fetuses of diabetic mothers was, however, less prominent than those of normal fetuses during 32 to 35 gestaional weeks, whereas those accelerations were observed at same extent at 36 gestational weeks. Our findings indicate that delay in maturation of CNS in fetuses of diabetic mothers occurred during 32 to 35 gestational weeks. Study on maternal factors regarding maturity in fetuses of diabetic mothers showed poor correlation between the acceleration and the levels of maternal plasma glucose and $\mathrm{HbA}_{1}$. The acceleration of heavy for date group tended to be less frequent than that of appropriate for date group in fetuses of diabetic mothers.
\end{abstract}

Key words: fetal heart rate acceleration - fetal movement - nonstress test diabetic pregnncy - fetal maturity

\section{Introduction}

The nonstress test (NST) is a measure of normal fetal movement (FM) and accompanying fetal heart rate (FHR) acceleration that is useful for perinatal fetal evaluation. NST findings during the second trimester of pregnancy have been examined since the discovery by Bishop (1981) of nonreactive patterns in a high percentage of fetuses before the 30 th week. Recently, the relation between FM and FHR acceleration has been associated with the development of control over FHR by the cen- tral nervous system (CNS). In this study, the authors used the NST to compare the development of heart rate control in fetuses of normal and diabetic pregnancies.

\section{Materials and Methods}

Twenty pregnancies in which the maternal risk factors were low or absent are shown in Table 1. The NST was performed a total of 115 times between the 24 th and 36 th weeks. There were 16 diabetic pregnancies in which the NST was performed 
at regular from intervals from the 28 th to the 36 th week (Table 1). Each NST was performed between 9:00 and 12:00 a.m., and recordings were obtained for at least $50 \mathrm{~min}$. The data from the diabetic pregnancies are included in Tables 1 and 2 . The maternal ages, White's classifications, hemoglobin $\mathrm{A}_{1}\left(\mathrm{Hb} \mathrm{A}_{1}\right)$ and mean plasma glucose levels are indicated. The control plasma glucose (PG) was rated as good (fasting PG: $<100 \mathrm{mg} / \mathrm{dl}, 120 \mathrm{~min} .:<120$ $\mathrm{mg} / \mathrm{dl}$ ), fair (fasting PG: $100 \sim 115 \mathrm{mg} / \mathrm{dl}$, $120 \mathrm{~min}$. : $120 \sim 170 \mathrm{mg} / \mathrm{dl}$ ), or poor (fasting PG: $\geqq 115 \mathrm{mg} / \mathrm{dl}, \quad 120 \mathrm{~min} .: \geqq 170 \mathrm{mg}$ $/ \mathrm{dl})$. The neonates were evaluated accord- ing to Nishida's neonatal body weight curve (Nishida et al. 1984) as appropriate for date (AFD), heavy for date (HFD), or light for date (LFD). This evaluation, the Apgar scores and the complications are shown in Table 2. Acceleration was divided into two groups, acceleration I $(\geqq 15 \mathrm{bpm}$ and $\geqq 15$ sec. $)$ and acceleration $\Pi(10 \sim 15$ bpm and $10 \sim 15$ sec.). Fetal movements (FMs) were assessed according to the maternal perception of FMs and tocodynamometrically apparent spike waves. All FMs within a $10 \mathrm{sec}$. period were considered to be a single movement.

TABLE 1

Clinical data on normal and diabetic pregnancies

\begin{tabular}{|c|c|c|c|}
\hline & & $\begin{array}{c}\text { Normal pregnancy } \\
\text { (115 fetuses })\end{array}$ & $\begin{array}{c}\text { Diabetic pregnancy ( } 16 \text { cases) } \\
\text { White class B } 12 \text { cases } \\
\text { class D } 4 \text { cases }\end{array}$ \\
\hline $\begin{array}{l}\text { Neonatal } \\
\text { outcome }\end{array}$ & $\begin{array}{l}\text { Gastational age } \\
\text { Birth weight } \\
\text { Apgar score }\end{array}$ & $\begin{array}{c}39 w 1 d(37 w 3 d-40 w 4 d) \\
3118 g(2898-3432 g) \\
9.2(7-10)\end{array}$ & $\begin{array}{c}36 w 4 d(32 w 3 d-39 w 5 d) \\
3115 g(2240-3724 g) \\
8.6(6-9)\end{array}$ \\
\hline
\end{tabular}

TABLE 2

Clinical profiles of diabetic mothers and newborns

\begin{tabular}{|c|c|c|c|c|c|c|c|c|c|}
\hline \multirow{2}{*}{$\begin{array}{l}\text { case } \\
\text { No }\end{array}$} & \multirow{2}{*}{ age } & \multirow{2}{*}{$\begin{array}{l}\text { White } \\
\text { class }\end{array}$} & \multirow{2}{*}{$\begin{array}{l}\text { control } \\
\text { level* }\end{array}$} & \multirow{2}{*}{$\begin{array}{c}\mathrm{Hb} \mathrm{A}_{1} \\
(\%)\end{array}$} & \multicolumn{5}{|c|}{ neonatal outcome } \\
\hline & & & & & $\begin{array}{l}\text { gestation } \\
\text { (weeks) }\end{array}$ & $\begin{array}{c}\text { birth weight } \\
(\mathrm{g})\end{array}$ & $\begin{array}{c}\text { relative birth } \\
\text { weight }\end{array}$ & $\begin{array}{c}\text { Apgar } \\
\text { score }\end{array}$ & morbidity \\
\hline 1 & 33 & $\mathrm{D}$ & $\mathrm{P}$ & 6.1 & 37 & 3700 & $\mathrm{H}$ & 9 & $(+)$ \\
\hline 2 & 29 & $\mathrm{D}$ & $\mathrm{P}$ & 6.7 & 38 & 3502 & A & 9 & $(-)$ \\
\hline 3 & 37 & B & $\mathrm{P}$ & 8.9 & 38 & 3260 & $\mathrm{~A}$ & 9 & $(-)$ \\
\hline 4 & 30 & B & $\mathrm{P}$ & 6.3 & 37 & 2720 & A & 9 & $(-)$ \\
\hline 5 & 35 & B & $\mathrm{P}$ & 9.1 & 37 & 3482 & $\mathrm{H}$ & 9 & $(-)$ \\
\hline 6 & 38 & B & $F$ & 8.1 & 36 & 3496 & $\mathrm{H}$ & 9 & $(+)$ \\
\hline 7 & 28 & $\mathrm{D}_{3}$ & $\mathrm{P}$ & 8.0 & 35 & 2580 & A & 9 & $(+)$ \\
\hline 8 & 29 & B & $\mathrm{P}$ & 7.9 & 36 & 3404 & $\mathrm{H}$ & 9 & $(+)$ \\
\hline 9 & 36 & B & $F$ & 7.9 & 37 & 3660 & $\mathrm{H}$ & 9 & $(+)$ \\
\hline 10 & 33 & B & $\mathrm{F}$ & 8.4 & 39 & 3140 & A & 6 & $(-)$ \\
\hline 11 & 30 & B & $\mathrm{F}$ & 7.4 & 38 & 2900 & A & 6 & $(-)$ \\
\hline 12 & 30 & $\mathrm{D}_{3}$ & $\mathrm{~F}$ & 8.7 & 32 & 2240 & A & 9 & $(+)$ \\
\hline 13 & 30 & B & $\mathrm{P}$ & 7.8 & 36 & 2900 & A & 9 & $(+)$ \\
\hline 14 & 31 & B & $\mathrm{P}$ & 7.6 & 36 & 3370 & $\mathrm{H}$ & 9 & $(-)$ \\
\hline 15 & 35 & B & $\mathrm{P}$ & 9.9 & 36 & 3724 & $\mathrm{H}$ & 8 & $(+)$ \\
\hline 16 & 37 & $\mathrm{~B}$ & $\mathrm{P}$ & 7.8 & 36 & 2408 & A & 9 & $(-)$ \\
\hline
\end{tabular}

* G: good F: fair P: poor

** $\mathrm{H}$ : heavy for date $\mathrm{A}$ : appropriate for date 


\section{Results}

\section{Normal pregnancies}

Weekly NST findings during normal pregnancies were expressed as the frequency of acceleration during $20 \mathrm{~min}$. (Table 3). There was a significant increase in acceleraiton $I$, from $2.7 \pm 1.2$ at $28 \sim 29$ weeks to $5.3 \pm 2.1$ at $30 \sim 31$ weeks. Thereafter, statistically significant increases were not seen. The frequency of acceleration II also increased, but not as much as acceleration I, from $1.0 \pm 1.8$ at $24 \sim 25$ weeks to $1.6 \pm 1.3$ at $26 \sim 27$ weeks. Fig. 1 . shows the FMs associated with acceleration as a percentage of all FMs. The number of FMs accompanied by acceleration $I$ increased significantly at $28 \sim 31$ weeks; but acceleration $I I$, although increased as compared to acceleration $\mathrm{I}$ at $24 \sim 27$ weeks, did not increase with the increase in duration of pregnancy. The incidence of acceleration I accompanied by FM, as a percentage of total acceleration I was also increased significantly at $28 \sim 31$ weeks (Fig. 2).

\section{Diabetic pregnancies}

The weekly frequency of acceleration measured by the NST in diabetic pregnancies is shown in Table 4. The frequency of acceleration I increaed from $2.8 \pm 1.6$ at $30 \sim 31$ weeks to $4.2 \pm 2.1$ at $32 \sim 33$ weeks. Accelerarion II followed the same trend as a normal pregnancy.

TABLE 3

Fetal heart rate acceleration in normal pregnancy

\begin{tabular}{cccccccc}
\hline \multirow{2}{*}{ FHR change } & \multicolumn{7}{c}{ Gestational week } \\
\cline { 2 - 8 } & $24-25$ & $26-27$ & $28-29$ & $30-31$ & $32-33$ & $34-35$ & $36-$ \\
\hline Acceleration I & $0.9 \pm 0.7$ & $1.0 \pm 1.1$ & $2.7 \pm 1.2$ & $5.3 \pm 2.1$ & $7.8 \pm 1.9$ & $8.6 \pm 1.3$ & $8.9 \pm 1.4$ \\
Acceleration II & $1.0 \pm 1.8$ & $1.6 \pm 1.3$ & $2.1 \pm 1.5$ & $3.1 \pm 2.3$ & $1.6 \pm 1.1$ & $1.0 \pm 0.6$ & $1.1 \pm 0.7$ \\
\hline $\mathrm{n}=$ & 11 & 12 & 16 & 19 & 18 & 20 & 19 \\
\hline
\end{tabular}

The values are mean $\pm S . D$.

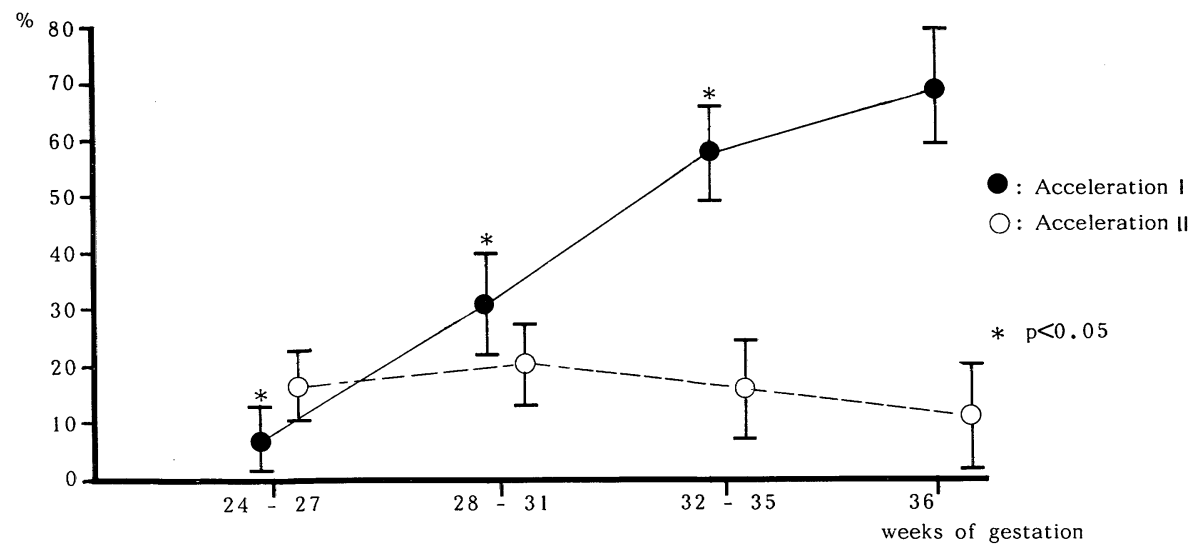

Fig. 1. Fetal heart rate acceleration: fetal movement ratio in normal pregnancy. 


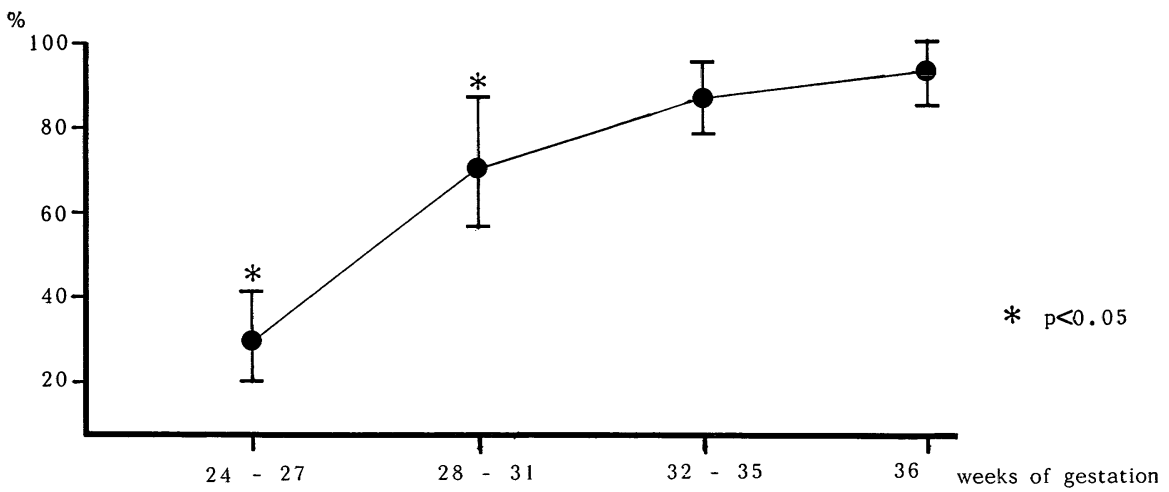

Fig. 2. Acceleration I associated with FM: total acceleration I ratio in normal pregnancy.

TABLE 4

Fetal heart rate acceleration in diabetic pregnancy

\begin{tabular}{cccccc}
\hline \multirow{2}{*}{ FHR change } & \multicolumn{5}{c}{ Gestational week } \\
\cline { 2 - 6 } & $28-29$ & $30-31$ & $32-33$ & $34-35$ & $36-$ \\
\hline Acceleration I & $1.8 \pm 1.5$ & $2.8 \pm 1.6$ & $4.2 \pm 2.1$ & $5.6 \pm 1.5$ & $7.8 \pm 1.8$ \\
Acceleration II & $0.7 \pm 0.9$ & $2.2 \pm 1.0$ & $1.4 \pm 0.8$ & $1.6 \pm 0.7$ & $1.8 \pm 0.9$ \\
\hline $\mathrm{n}=$ & 8 & 10 & 16 & 16 & 14 \\
\hline
\end{tabular}

The values are mean \pm S.D.

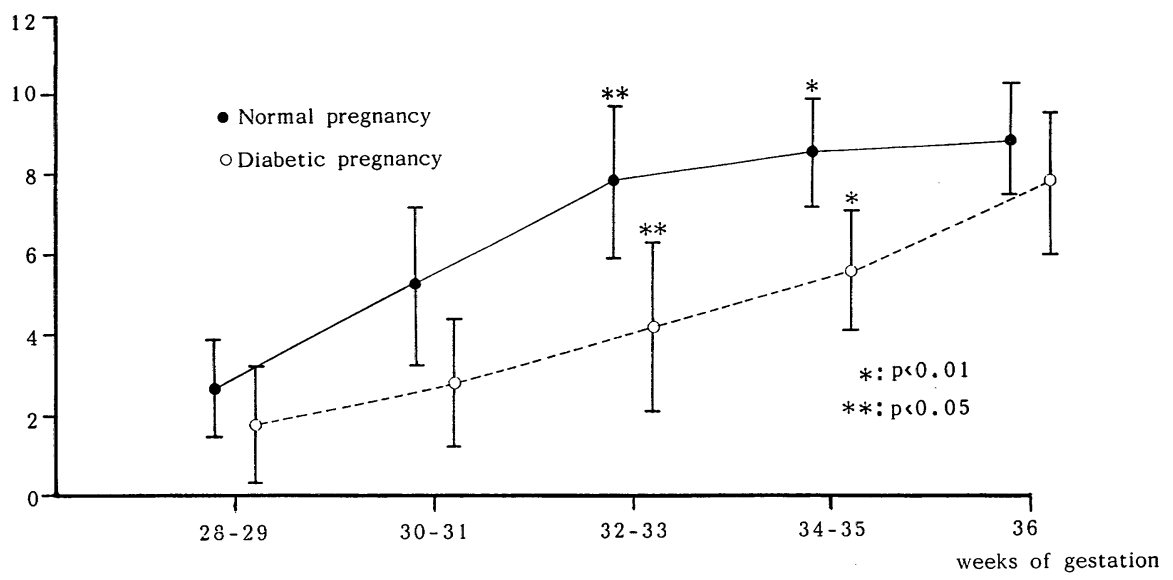

Fig. 3. The number of acceleration I's in normal and diabetic pregnancy. 
$\%$

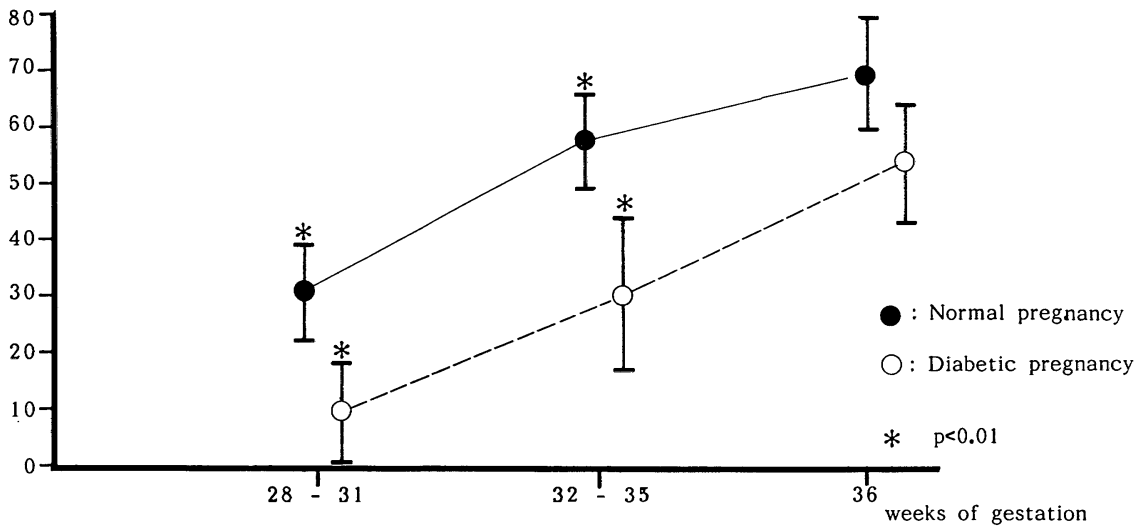

Fig. 4. Fetal heart rate acceleration: fetal movement ratio in diabetic pregnancy.

$\%$

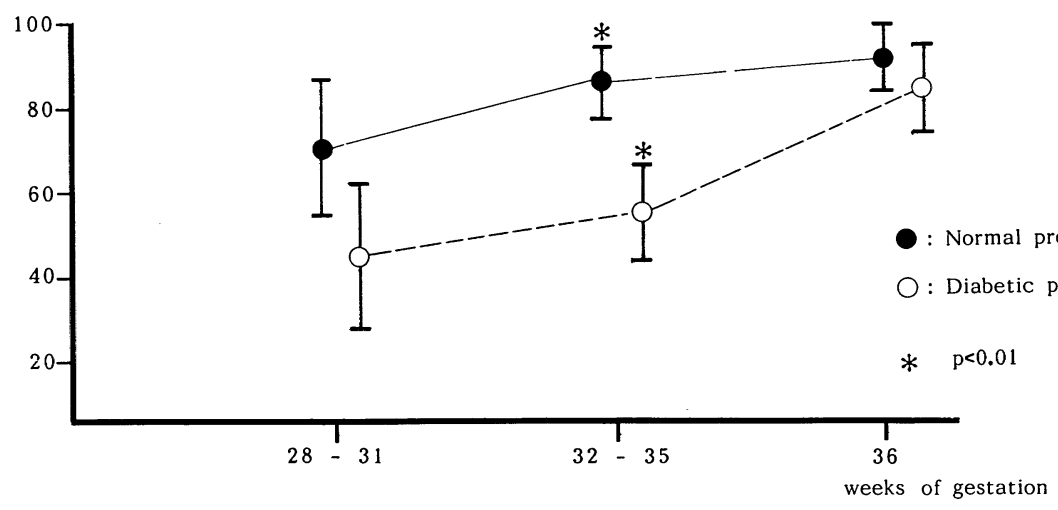

Fig. 5. Acceleration I associated with FM: total acceleration I ratio in diabetic pregnancy.

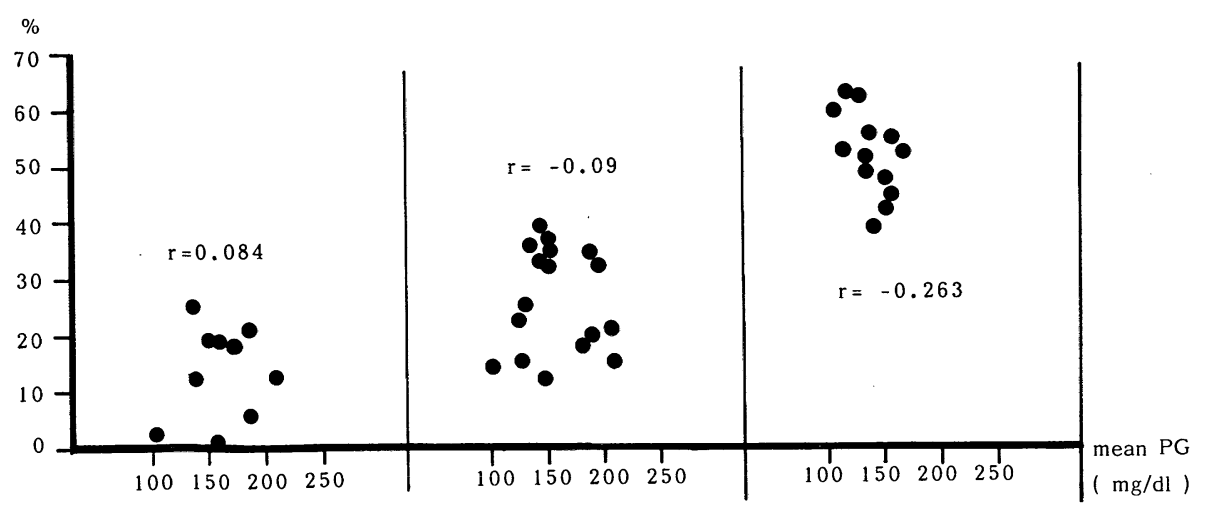

Fig. 6. Correlation between AFMR and mean plasma glucose in diabetic pregnancy. (AFMR; Acceleration: Fetal Movement Ratio) 
3. Comparison of NST findings in normal and diabetic pregnancies

Acceleration was significantly less frequent in diabetic than in normal pregnancies at $32 \sim 33$ weeks $(\mathrm{p}<0.05)$ and at $34 \sim 35$ weeks $(\mathrm{p}<0.01)$ (Fig. 3$)$. FMs accompanied by acceleration, as a percentage of FMs and acceleration I accompanied by FM, as a percentage of all acceleration I were significantly lower at $32 \sim 35$ weeks
( $\mathbf{p}<0.01)$ in diabetic than in normal pregnancies (Fig. 4, 5).

4. NST and plasma glucose control in diabetic pregnancise

No significant correlation was seen between mean maternal plasma glucose levels or $\mathrm{Hb} \mathrm{A}_{1}$ and the percentage of FMs accompanied by acceleration I (Fig. 6, 7).

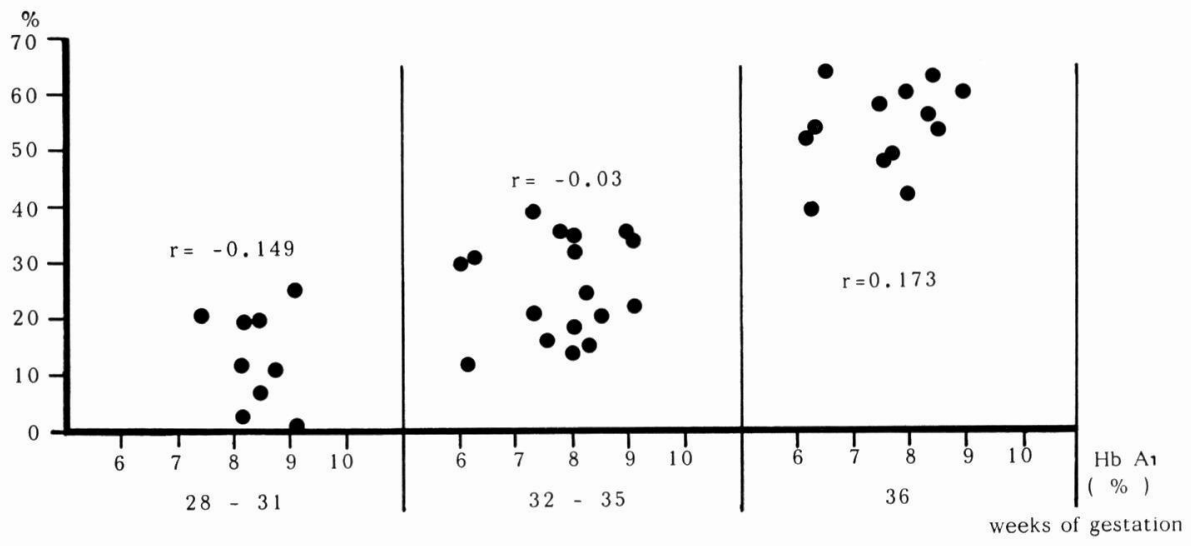

Fig. 7. Correlation between AFMR and $\mathrm{Hb} \mathrm{A}_{1}$ in diabetic pregnancy.

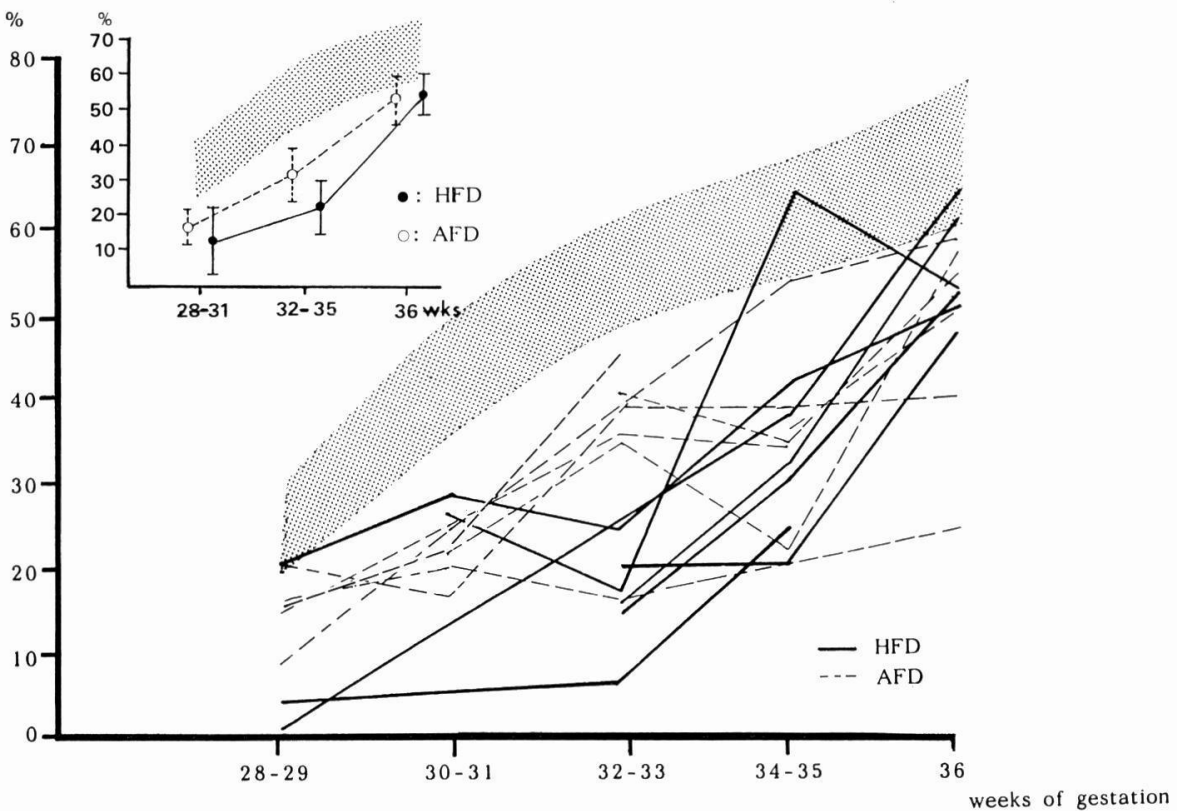

Fig. 8. The relation between AFMR and neonatal birth weight. 


\section{NST and neonatal body weight from dia- betic mothers}

Neonatal body weights were classified as AFD, HFD, or LFD (Nishida et al. 1984). Fig. 8. shows the changes in percentage of FMs accompanied by acceleration $I$ at $28 \sim 36$ weeks for AFD and HFD infants. The HFD infants had less acceleration I associated with FM than the AFD infants.

\section{Discussion}

Nonreactive patterns were frequently observed by Bishop (1981) using the NST before the 30 th week of gestation. They also reported no difference in the risk to fetuses or neonates between reactive patterns and nonreactive patterns, and concluded that the nonreactive patterns before the 30 th week was caused by incomplete development of heart rate control due to immaturity of the central nervous system. Sorokin et al. (1982) compared NST findings of fetuses at $20 \sim 22$ weeks to those at $28 \sim 30$ weeks of gestation and found a stronger association between FM and FHR acceleration in the older fetuses. In another study (Matsunaga et al. 1985), using NST on fetuses of normal pregnancies at regular intervals, the development of central nervous system control over FHR occurred during the 20 th to the 32 nd week. It appears from these findings that NST can be used as a method to clinically evaluate the development of FHR control. It has been noted that the organs of fetuses and neonates with diabetic mothers are underdeveloped. A lower production of pulmonary surfactant has been observed to result in an increased incidence of respiratory distress syndrome (Hallman and Teramo, 1979). Fetal hyperinsulinism is thought to be responsible for this lowered production of pulmonary surfactant. Poor blood glucose control in the diabetic mother raises fetal blood glucose levels, which in- hibits the action of cortisol on the production of pulmonary surfactant and retards fetal lung maturity.

It is also known that higher than normal levels of glucose are supplied to the brain of fetuses of diabetic pregnancies, preventing a rise of blood catecholamines in the last trimester. Artal et al. (1980) measured catecholamine levels in the amniotic fluid and found them to be lower in diabetic than in normal pregnancies. Most catecholamines in the amniotic fluid are probably of fetal origin (Diver et al. 1981). Since amniotic catecholamines are indicative of the maturation of adrenergic tissue, it is assumed that amniotic catecholamines are products of fetal brain maturation. Lower catecholamine levels in the amniotic fluid may be indicative of a delayed maturation of the brain in the fetuses of diabetic pregnancies. In neonates of diabetic mothers, Schulte et al. (1969) observed a prolongation of the rapid eye movement (REM) sleep cycle, a phenomenon frequently observed in premature infants. The CNS in these neonates was relatively immature when compared to neonates from normal pregnancies. Dierker et al. (1982) reported an association between fetal cyclicity of active and quiet phases and the development of the fetal CNS. They discovered that fetal cyclicity was less mature in the fetuses of diabetic pregnancies than in those of normal pregnancies.

In the present study, FMs and the percentage of acceleration accompanied by FMs at $32 \sim 35$ weeks of gestation was significantly lower in fetuses of diabetic pregnancies than in those of normal pregnancies. The difference between the two groups may occur because fetal control of the heart rate in fetuses of diabetic pregnancies is less mature in comparison to the control of fetuses of normal pregnancies, until the 35 th week. The relationship between retardation of FHR control and maternal plasma glucose control was 
also examined. The mean plasma glucose and $\mathrm{Hb} \mathrm{A}_{1}$ are considered to be good indicators of diabetic control (Vintzileos and Thompson, 1980). There is a weak correlation between the control of plasma glucose and the retardation of FHR control as judged by acceleration. However, an association between delayed development of FHR control and maternal plasma glucose cannot be dismissed, because there was a tendency toward delayed development of FHR control in HFD infants, which probably reflects matenal plasma glucose control.

\section{References}

Artal, R., Platt, L. D., Kammula, R. K., Strassner, H.T. and Gratacos, J. (1980). Concentrations of metanephrine in the amniotic fluid as an indicator of fetal stress. Dev. Neurosc. 8, 449-452.

Bishop, E.H. (1981). Fetal acceleration test. Am. J. Obstet. Gynecol. 141, 905-909.

Dierker, L. J., Pillay, S., Sorokin, Y. and Rosen, M.G. (1982a). Active and quiet periods in the preterm and term fetus. Obstet. Gynecol. 60, 65-70.

Dierker, L. J. Pillay, S., Sorokin, Y. and Rosen, M.G. (1982b). The change in fetal activity period in diabetic and non-diabetic pregnancies. Am. J. Obstet. Gynecol. 143, 181-185.

Divers, W.A., Wilkes, M.M., Babaknia, A. and YEN, S.S.C. (1981). An increase in catecholamines and metabolites in the amniotic fluid compartment from middle to last gestation. Am. J. Obstet. Gynecol. 139, 483-486.

Hallman, M. and Teramo, K. (1979). Amniotic fluid phospholipid profiles as a prediction of fetal maturity in diabetic pregnancies. Obstet. Gynecol. 54, 703-707.

Matsunaga, T., Hamada, T., Matunaga, T., Tetsuo, M., Ishimatsu, J. et al (1985). Studies on fetal movement and fetal heart rate changes during 20 to 32 week gestation. Kurume Med. J. 32, 121-126.

Nishida, H., Sakanoue, M., Kurachi, K., Asada, A. and Kubo, S. (1984). Fetal growth curve of Japanese. Acta Neonat. Jap. 20, 90-97.

Schulte, F. J., Lasson, U., Parl, U., Norte, R. and JURGEN, U. (1969). Brain and behavioral maturation in newborn infants of diabetic mothers. Neuroped. 1, 36-43.

Sorokin, Y., Dierker, L. J., Pillay, S. K., ZAdor, I. E., Schreiner, M.L. et al. (1982). The association between fetal heart rate patterns and fetal movements in pregnancies between 20 and 30 weeks gestation. Am. J. Obstet. Gy necol. 143, 243-249.

Vintzileos, A.M. and Thompsom, J.P. (1980). Glycohemoglobin determinations in normal pregnancy and insulin-dependent diabetics. Obstet. Gynecol. 56, 435-439. 